\title{
OCUPAÇÃO PROFISSIONAL E RENDA DE EGRESSOS DE UM PROGRAMA DE PÓS-GRADUAÇÃO EM CONTABILIDADE
}

\author{
Fabiana Frigo Souza ${ }^{1}$, Rogério João Lunkes ${ }^{1}$, Valdirene Gasparetto ${ }^{1}$ \\ ${ }^{1}$ Universidade Federal de Santa Catarina - UFSC \\ fabiiana fs@hotmail.com, rogeriolunkes@hotmail.com, valdirene.gasparetto@ufsc.br
}

\begin{abstract}
RESUMO
Nos anos recentes aumentou, no Brasil, o número de instituições credenciadas a oferecer cursos stricto sensu, e tais cursos, à medida em que elevam o nível de conhecimentos e especialização das pessoas, tendem melhorar sua empregabilidade e aumentar os rendimentos. Nesse sentido, este estudo tem o objetivo de identificar o perfil de ocupação profissional e de renda dos egressos do Programa de Pós-Graduação em Contabilidade da Universidade Federal de Santa Catarina. Para atender o objetivo proposto, foi elaborado um questionário, enviado a todos os egressos do Programa, obtendo 51 respostas, o que representa 64,6\% do total de egressos do Programa (mestres em Contabilidade). Os resultados mostram que houve migração das atividades executadas pelos egressos, já que antes de ingressar no curso a maioria (82\%) possuía a principal atividade profissional ligada ao mercado e após a conclusão do mestrado a maioria (54\%) passou a exercer atividade ligada à academia. Observou-se que 27\% dos mestres iniciou curso de doutorado e $74 \%$ dos que não iniciaram, pretendem fazê-lo. Os rendimentos percebidos pelos egressos também foram alavancados após a conclusão do mestrado, corroborando os resultados de pesquisas anteriores.
\end{abstract}

Palavras-chave: Mestrado. Teoria do Capital Humano. Contabilidade.

\begin{abstract}
In recent years increased, in Brazil, the number of institutions accredited to offer courses stricto sensu, and such courses as they raise the level of knowledge and specialization of people tend to improve their employability and raise incomes. Thus, this study aims to identify and analyze the profile of professional occupation and income of graduates of the Graduate Program in Accounting from the Federal University of Santa Catarina. To meet the proposed objective, was elaborate a questionnaire, sent to all graduates of the program, getting 51 responses, representing $64.6 \%$ of total graduates from the program (Masters in Accounting). The results show that there was migration of activities performed by graduates, already that before joining the course the majority (82\%) possessed the main professional activity linked to the market and upon completion of the master's most (54\%) began to exert activity connected the academy. It was observed that $27 \%$ of masters initiated the course for a doctorate and that $74 \%$ who did not initiate, intend to do so. Proceeds perceived by graduates were also leveraged upon completion of the master, corroborating the results of previous research.
\end{abstract}

Keywords: Master's Degree. Human Capital Theory. Accounting.

\section{Introdução}

O estudo e a especialização dos indivíduos aumenta seu capital humano, conforme preconiza a teoria do capital humano (CUNHA; CORNACHIONE JUNIOR; MARTIN, 2010). A partir disso, conforme Cunha, Cornachione Junior e Martin (2010), o indivíduo poderá ter a expectativa de ser recompensado pessoal e financeiramente pelo investimento realizado. Este investimento pode ser financeiro ou em termos de esforços para realizar graduação, atualizações e pós-graduação. 
Martins (2009) descreve que a Teoria do Capital Humano fundamenta-se no conceito de que a aquisição de novos conhecimentos e habilidades aumenta o valor do capital humano das pessoas, com consequências em sua empregabilidade, produtividade e rendimento potencial. Isto faz com que aqueles que empregam maior tempo no processo de aquisição de conhecimento possuam maiores chances de terem melhores empregos e rendimentos, situação que foi observada por Cunha (2007, p. 9), quando cita que "adultos com maiores níveis educacionais teriam maiores possibilidades de trabalho e, quando empregados, melhores salários".

Menezes Filho (2002) e Cunha (2007) descrevem que os indivíduos com 15 a 16 anos de estudo, que representa o superior completo, têm um rendimento salarial médio quase doze vezes maior do que aqueles sem escolaridade, enquanto com curso stricto sensu a diferença aumenta para dezesseis vezes, o que significa que aparentemente o mestrado auxilia no retorno financeiro, duplicando o salário de um graduado após a obtenção do título de mestre, ou seja, o retorno financeiro se dá proporcionalmente ao tempo de estudo.

A relação entre conhecimento/aperfeiçoamento e maiores rendimentos não se verifica somente no Brasil. Segundo Blaug (1975), em todas as economias as pessoas que apresentam maior nível de educação percebem, em média, rendimentos mais elevados, quando se comparam pessoas da mesma idade, o que confirma que o conhecimento e o aperfeiçoamento trazem maiores retornos, e que quanto mais o indivíduo adquire conhecimento, maiores são suas chances de possuir maiores rendimentos e ofertas de emprego.

Observa-se que vem aumentando significativamente, no Brasil, o número de instituições credenciadas a oferecer programas de pós-graduação em nível de mestrado e doutorado em todas as áreas do conhecimento. Em 2010, foram formados 35.965 mestres no país, contingente que passou para 42.780 formados em 2012. A quantidade de doutores titulados subiu de 11.210 para 13.879 no mesmo período, enquanto os concluintes de mestrados profissionais (formação voltada para especificamente para o mercado de trabalho) foram de 3.236 para 4.251 em 2012, considerando todas as áreas do conhecimento (CAPES, 2014).

A partir desse contexto, surge a problemática da pesquisa: qual o panorama de ocupação profissional e de renda dos egressos do Programa de Pós-Graduação em Contabilidade stricto sensu da Universidade Federal de Santa Catarina (UFSC)? Partindo da questão problema tem-se o seguinte objetivo geral: identificar o perfil de ocupação profissional e de renda dos egressos do Programa de Pós-Graduação em Contabilidade da Universidade Federal de Santa Catarina. Como objetivos específicos pretende-se: i) identificar se os egressos continuaram estudando em programas de pós-graduação da mesma universidade ou em outros, após a conclusão do curso, ii) verificar se os egressos atuam profissionalmente na área acadêmica, e o perfil da ocupação, iii) avaliar se os egressos atuam em programas de pós-graduação, iv) comparar os rendimentos percebidos pelos egressos antes e após a conclusão do curso.

O estudo contribui ao verificar se os cursos de pós-graduação em contabilidade no Brasil estão atingindo seus objetivos institucionais, o que também pode ser interessante para o planejamento de novos cursos e alocação de recursos.

Neste sentido, a presente pesquisa se justifica ao analisar o atual panorama dos egressos do Programa de Pós-Graduação em Contabilidade da UFSC, sendo esta uma forma de medir o retorno gerado pelo mestrado. O estudo também pode servir de auxílio para aqueles que pretendem ingressar no Programa de Pós-Graduação em Contabilidade, ao mostrar o retorno que esse curso pode gerar, bem como para instituições de fomento à pesquisa.

Para atender o objetivo proposto, o trabalho está estruturado em quatro seções, iniciandose por esta introdução. Na segunda seção apresenta-se referencial teórico, após traz-se a apresentação e análise dos dados, e na quarta seção mostra-se as conclusões do trabalho. Ao final são listadas as referências utilizadas. 


\section{Referencial Teórico}

Esta seção é constituída do referencial teórico, dando enfoque a teoria do capital humano e as pesquisas realizadas anteriormente.

\subsection{Teoria do capital humano}

A teoria do capital humano trata da forma como o conjunto de capacidades do ser humano, neste sentido entendido pelos conhecimentos, habilidade e atitudes que tendem a gerar resultados positivos economicamente (MARTINS, 2009, p. 25), assim quanto maiores as capacidades produtivas de um indivíduo maior será o seu capital humano. Cunha (2007) define que a chave da teoria do capital humano está no fato de que a aquisição de conhecimento aumenta o capital humano de um indivíduo, alavancando sua capacidade, produtividade e consequentemente seu rendimento pessoal, gerando assim um aumento também na sua renda futura.

Moraes (2009, p. 23) cita que o capital é caracterizado como humano por ser parte do ser humano, do homem e como capital por representar fonte de recursos e satisfações futuras, sendo uma forma de adquirir satisfação ou rendimentos futuros maiores por meio do conhecimento. Para Lima (1980, p. 226), a Teoria do Capital Humano tem a seguinte lógica:

\footnotetext{
a) As pessoas se educam;

b) A educação tem como principal efeito mudar suas "habilidades" e conhecimentos;

c) Quanto mais uma pessoa estuda, maior é sua habilidade cognitiva e sua produtividade;

d) Maior produtividade permite que as pessoas recebam maiores rendas.
}

Becker (1962), Blaug (1976) e Martins (2009) descrevem que a Teoria do Capital Humano fundamenta-se no conceito de que a aquisição de mais conhecimentos e habilidades melhora o valor do capital humano das pessoas, consequentemente aumenta a empregabilidade, produtividade e rendimento potencial. Isto significa que o indivíduo que se especializa e adquire conhecimento, terá maior rendimento potencial.

O aumento de renda pode ocorrer a partir da aquisição de conhecimento e consequentemente do aumento do seu capital humano, ou seja, as pessoas podem aumentar o conjunto de opções e escolhas disponíveis (SCHULTZ, 1961; MARTINS, 2009), tendo assim maior controle sobre a renda desejada. Blaug $(1975$, p. 1) descreve que:

\footnotetext{
em todas as economias de que temos notícia, as pessoas que receberam mais educação percebem, em média, rendimentos mais elevados do que aqueles que receberam menos, pelo menos quando se comparam pessoas da mesma idade. Em outras palavras, um acréscimo de educação é compensador, sob a forma de rendimentos vitalícios mais altos.
}

O capital humano ocupa importante papel no crescimento econômico de um país, uma vez que influencia diretamente a criação de tecnologia, a produtividade e qualidade de vida (FERREIRA, 2008; MARTINS, 2009). Isto indica que o capital humano tem um papel fundamental no desenvolvimento e crescimento de um país.

Uma das formas de aquisição de capital humano é a partir da pós-graduação stricto sensu que pode ser entendida como sendo um sistema sobreposto a graduação, em que busca o aprofundamento do estudante quanto aos conhecimentos profissionais e culturais, buscando tornando-o mestre ou doutor (MARTINS, 2009, p. 36), sendo assim, uma forma de formar ou aumentar o capital humano que, segundo Cunha (2007, p. 13) ocorre por meio do desenvolvimento pessoal, seja pelo aumento dos seus conhecimentos, habilidades ou capacidades. 


\subsection{Pesquisas anteriores}

Nesta seção são apresentadas algumas pesquisas similares à deste trabalho, que buscaram avaliar o panorama dos egressos de programas de pós-graduação em contabilidade, resultado de buscas feitas nas bases de dados Scielo, Scopous, Spell e Google Scholar.

Machado (2003) analisou o retorno econômico-financeiro dos egressos dos cursos de Pós-Graduação lato sensu em Contabilidade da Universidade Federal da Paraíba, com informações coletadas a partir de questionários e uma amostra de 143 respondentes, do total de 363 egressos de 1988 a 2001 dos cursos de especialização na área contábil da instituição. Observaram que ampliação geral da formação, atualização e aprofundamento do conhecimento, troca de experiências, ampliação do círculo de relacionamentos, melhoria de desempenho no trabalho e capacitação para a pesquisa foram aspectos que tiveram satisfação em torno de 50\%, no entanto em relação a aumento dos rendimentos, promoção no trabalho, obtenção de novas oportunidades de trabalho e mudança de ocupação, a satisfação ficou abaixo de $38 \%$. Concluíram, a partir do estudo, que os cursos de especialização não proporcionaram resultados econômico-financeiros aos concluintes.

Neri (2005), em trabalho realizado com base nos microdados do Censo 2000 de diferentes cursos, tinha como objetivo identificar os maiores retornos econômicos do investimento educacional. Por meio da análise de salários e da capacidade de conquistar emprego após a formação, constatou que os mestres e doutores (principalmente em Administração, Medicina e Economia) possuem as maiores remunerações, cerca de $1.503 \%$ acima daqueles que nunca frequentaram a escola e quanto a facilidade na obtenção de emprego, o mestrado em Medicina apresenta 18 vezes mais oportunidade de ocupação em comparação a quem não frequentou a escola.

Cunha (2007) analisou, com base na teoria do capital humano, os doutores em Ciências Contábeis da FEA/USP. Foram aplicados questionários a 150 egressos e chegou à conclusão de que parte significativa dos doutores mantém a academia como principal atividade remunerada $(68,9 \%)$. Também observou um aumento de renda dos egressos, visto que antes do ingresso no doutorado 41,4\% percebiam rendimentos de até $\mathrm{R} \$ 5.000,00$ e após a conclusão do doutorado $45,4 \%$ percebiam rendimentos entre $\mathrm{R} \$ 5.000,00$ e $\mathrm{R} \$ 10.000,00$.

Moraes (2009) realizou estudo, sob a ótica do capital humano, com os mestres em Ciências Contábeis dos 14 programas de Mestrado em Contabilidade do Brasil. A partir de questionário junto a 64,4\% da totalidade de mestres em Ciências Contábeis do Brasil, observou que $55,6 \%$ da população pesquisada atua na docência, e que tanto na área acadêmica quanto na área privada houve migração de faixa salarial após a conclusão do curso.

Martins (2009), em uma análise do programa multi-institucional da UNB/UFPB/UFPE, a partir das percepções e avaliações dos mestres em Ciências Contábeis, tinha como objetivo analisar as influências geradas pelo título de Mestre em Ciências Contábeis deste Programa em termos de desempenho acadêmico e profissional. O estudo teve como amostra um total de 96 mestres - 70,07\% do total de mestres formados pela instituição entre 2002 e 2007 -, onde as informações foram coletadas a partir da aplicação de questionários. Concluiu que após a obtenção do título de mestre houve um crescimento das produções científicas, bem como dos rendimentos.

Dallabona, Oliveira e Rausch (2014) realizaram uma pesquisa junto aos 48 egressos do curso de mestrado do Programa de Pós-graduação em Ciências Contábeis da Universidade Regional de Blumenau com o objetivo de identificar os seus avanços pessoais e profissionais. Por meio da aplicação de questionário os autores identificaram que antes da obtenção do título de mestre 17 profissionais não possuíam experiência na área docente e após a titulação este número passou para 1, além disso, mais de $60 \%$ dos docentes possui remuneração acima de 4.905,00. 
Oliveira (2014) em sua pesquisa buscou verificar a atuação profissional e a na situação socioeconômica de egressos do curso de Mestrado em Contabilidade da UFBA por meio da aplicação de questionário a 10 dos 23 egressos. Com base nos questionários os autores identificaram que $90 \%$ dos respondentes entrou no mestrado com o objetivo de inserir-se na carreira docente e após a obtenção do título $80 \%$ exercia atividade docente, em contrapartida aos $20 \%$ que exerciam antes da titulação, além disso, observou-se aumento da remuneração entre os pesquisados.

\section{Aspectos metodológicos}

A pesquisa foi realizada junto aos egressos do Programa de Pós-Graduação em Contabilidade da UFSC e para a obtenção dos dados foram aplicados questionários disponibilizados em meio virtual com o envio do link da pesquisa via e-mail.

Quanto aos objetivos, o presente estudo é um trabalho descritivo. Gil (2002) define uma pesquisa descritiva como sendo aquela que tem como objetivo "a descrição das características de determinada população ou fenômeno ou, então, o estabelecimento de relações entre variáveis".

Para Triviños (1987), uma pesquisa tem caráter descritivo quando "pretende descrever com exatidão os fatos e fenômenos de determinada realidade".

No que diz respeito aos procedimentos, trata-se de um levantamento. Levantamento, segundo Gil (2002), caracteriza-se pela interrogação dos indivíduos pertencentes à população que se deseja estudar, solicitando informações para posteriormente fazer uma análise quantitativa das respostas obtidas.

Quanto à abordagem do problema, considera-se preponderantemente quantitativa, visto que apesar de possuir itens qualitativos, a pesquisa baseia-se na utilização de questionários e na análise dos mesmos. Conforme Richardson (1985), o método quantitativo "caracteriza-se pelo emprego da quantificação tanto nas modalidades de coleta de informações, quanto no tratamento dessas através de técnicas estatísticas" e tem como objetivo "garantir a precisão dos resultados, evitar distorções de análise e interpretação, possibilitando, consequentemente, uma margem de segurança quanto às inferências".

O questionário foi elaborado a partir da definição dos objetivos geral e específicos, buscando perguntas que trariam base para o atingimento dos objetivos e resposta à questão problema. Para auxiliar no processo de elaboração do questionário foram utilizados os questionários dos trabalhos de Cunha (2007), Moraes (2009), Martins (2009) e Machado (2003).

Um pré-teste do questionário foi realizado com três egressos a fim de se fazerem possíveis ajustes a partir de suas opiniões e percepções acerca das respostas solicitadas. Foi feita ainda uma análise em relação aos objetivos a fim de garantir que de posse das respostas haveria a possibilidade de atendimento de todos os objetivos. O questionário elaborado foi então convertido utilizando-se a base do Google Docs.

Primeiramente foi contatada a coordenação do Programa para obtenção dos nomes e emails dos egressos do Programa de Pós-Graduação em Contabilidade da UFSC. A partir da pesquisa realizada junto à coordenação, professores e no site do Programa de Pós-Graduação, foram identificados 79 mestres em Contabilidade formados pela UFSC.

Após a obtenção dos egressos, foi feita a aplicação definitiva dos questionários, por meio de envio do link onde a pesquisa se encontrava alocada, via e-mail, e, de posse dos dados, ocorre a análise e discussão dos resultados obtidos na pesquisa. A análise dos dados foi feita a partir do tratamento dos mesmos no Microsoft Excel, buscando responder o objetivo principal e os específicos.

Dos 79 egressos identificados, 51 responderam à pesquisa, o que representa $64,6 \%$ da totalidade dos egressos. A pesquisa foi realizada no período de 20/06 a 30/08 de 2013.

\section{Apresentação e análise dos resultados}


Este tópico foi dividido em três partes, iniciando com identificação e atuação dos discentes antes do início do mestrado. Em seguida apresenta-se uma análise quanto as questões que influenciaram a decisão por fazer o mestrado. O último tópico trata das atividades exercidas pelos pesquisados após a conclusão do mestrado.

\subsection{Identificação e atuação antes do início do mestrado}

Quanto à identificação dos mestres em Contabilidade formados pela UFSC, 49\% são do sexo feminino e $51 \%$ do sexo masculino, havendo um equilíbrio na proporção de homens e mulheres no curso, situação um pouco diferente da encontrada no trabalho de Cunha (2010), onde em relação ao doutorado, $84,8 \%$ eram do sexo masculino e $15,2 \%$ do sexo feminino, e no trabalho de Martins (2009), em relação ao mestrado, onde 65,64\% eram do sexo masculino e 34,37\% do sexo feminino. Em relação à graduação, 92\% dos egressos possuem graduação em Ciências Contábeis e $8 \%$ em Administração, não sendo identificado nenhum mestre que tenha formação em outro curso de graduação, resultado que se equipara ao de outros estudos como o de Moraes (2009), onde 79,4\% são graduados em Ciências Contábeis, 10\% em Administração, 4,6\% em Economia, 2,5\% nas áreas de Engenharia e outros cursos com 3,5\%. No que diz respeito ao local onde foi cursada a graduação, $43,1 \%$ se formaram na mesma universidade em que fizeram o mestrado, a UFSC, aproximadamente $54,9 \%$ em outras universidades e aproximadamente $2 \%$ não responderam à pergunta.

A pesquisa buscou identificar quais as atividades desenvolvidas pelos egressos antes de ingressarem no mestrado em Contabilidade. Observou-se que $27 \%$ dos egressos tinham atividade ligada à academia, o que corrobora com os resultados do trabalho de Martins (2009), que identificou que $29,17 \%$ dos seus respondentes possuíam a principal atividade remunerada ligada à academia.

Dos que exerciam atividade remunerada, a maioria trabalhava no setor privado, $39 \%$, ou seja, mesmo que aproximadamente $43 \%$ desses egressos tenham concluído sua graduação em uma universidade pública, como pode ser visto na figura 1, a maioria trabalhava no setor privado, seja na área acadêmica ou noutras atividades.

Figura 1 - Relação de trabalho da principal atividade remunerada antes de ingressar no mestrado

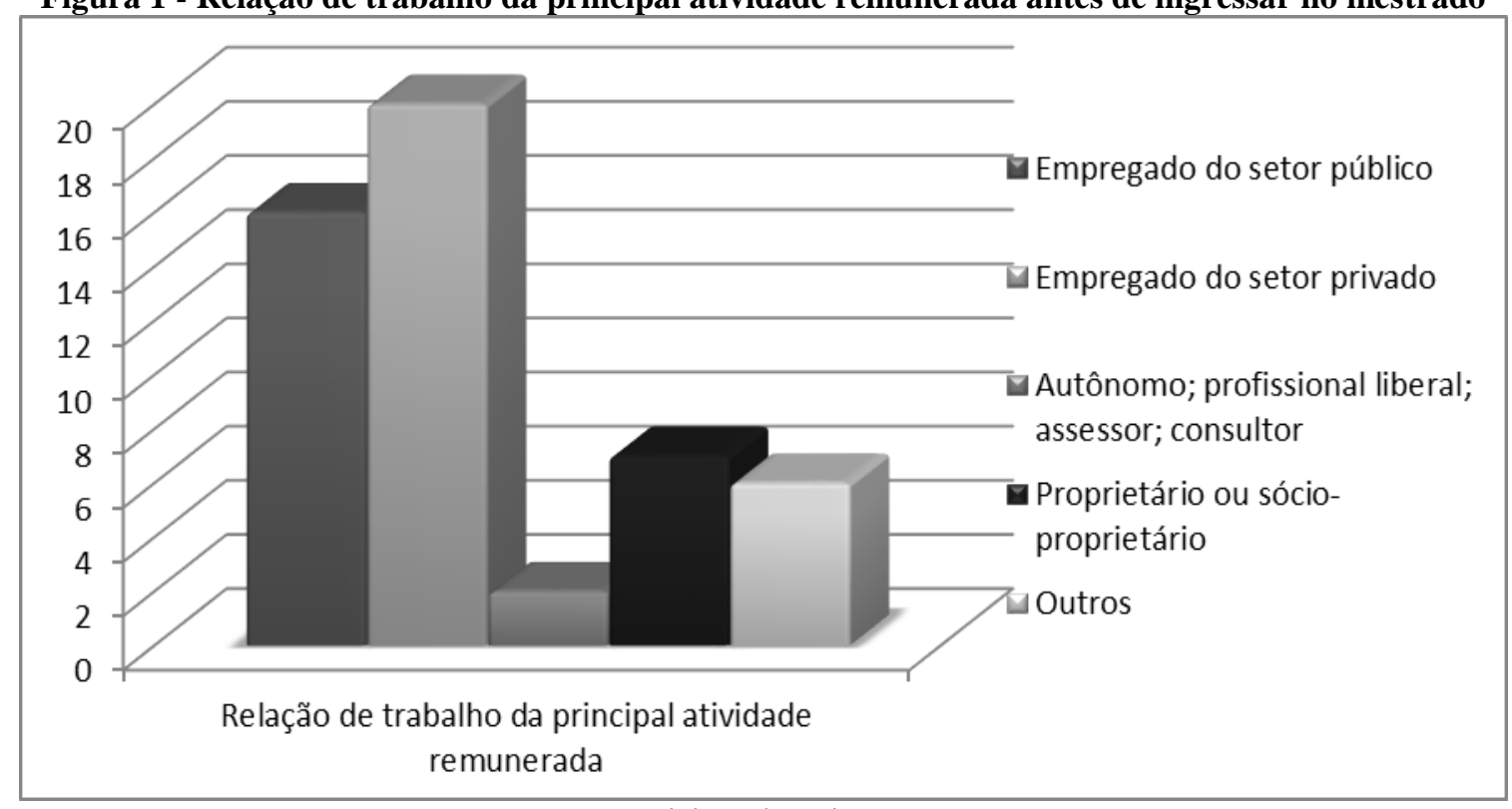

Fonte: Elaborado pelos autores

Antes de ingressar no curso de mestrado, apenas $18 \%$ possuíam atividade ligada à docência, sendo que desses, $37 \%$ trabalhavam em universidades, $37 \%$ em faculdades, $16 \%$ 
exerciam atividades em centros universitários e $10 \%$ em outros. Dos que exerciam atividades ligadas à docência, $70 \%$ o faziam em instituições privadas, tendo como forma de remuneração a hora/aula em $63 \%$ dos casos, além disso, $25 \%$ dos que exerciam atividade ligada à docência também estavam ligados a pesquisa.

Em termos de salário, como mostra a figura 2, antes de iniciar o mestrado, 27,7\% recebiam salários de até $\mathrm{R} \$ 2.000,00,40,4 \%$ tinham salários de $\mathrm{R} \$ 2.001,00$ a $\mathrm{R} \$ 5.000,00$ e $31,9 \%$ tinham salários acima de $\mathrm{R} \$ 5.001,00$, o que se situa próximo ao resultado da pesquisa de Martins (2009), que observou que a remuneração média antes do ingresso no mestrado era de $\mathrm{R} \$$ $3.968,31$.

Figura 2 - Renda antes de iniciar o mestrado

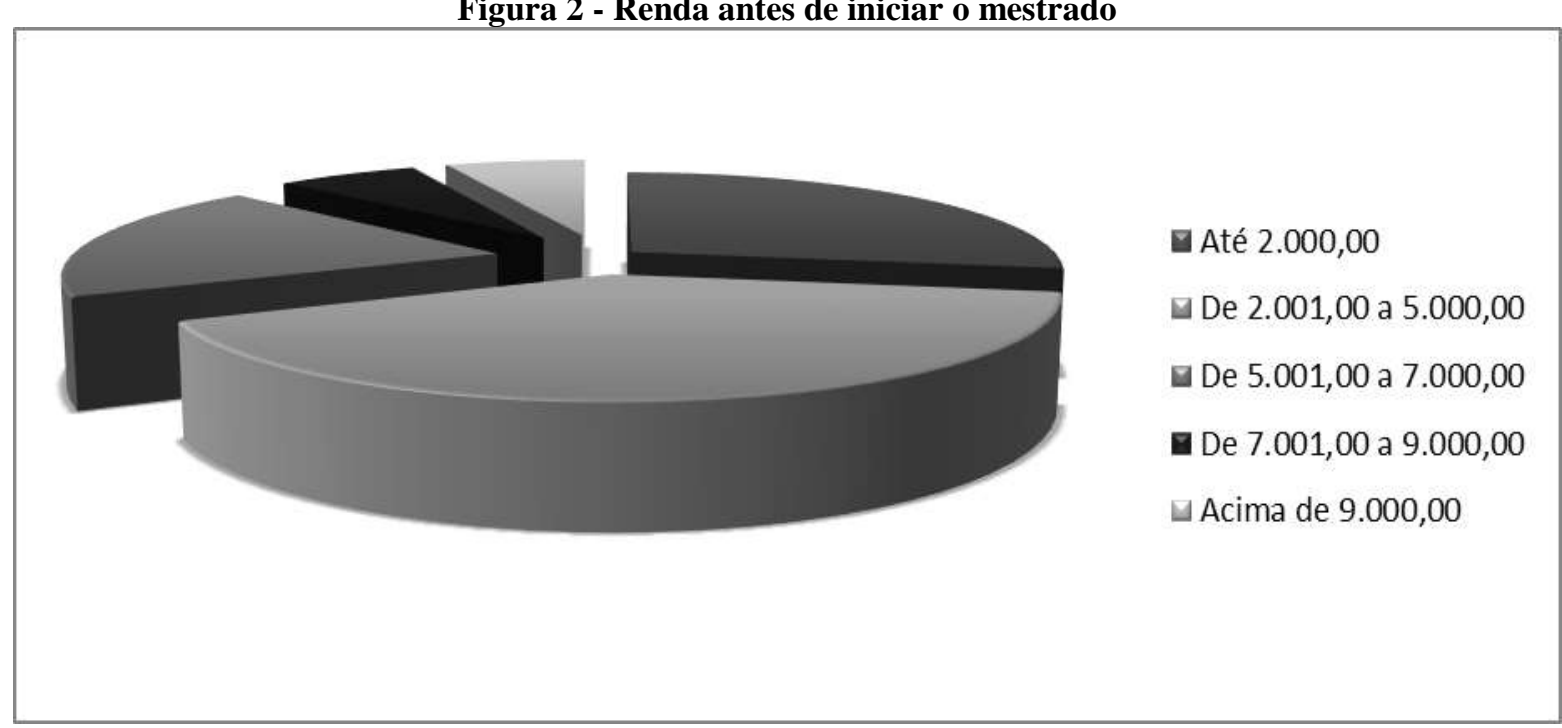

Fonte: Elaborado pelos autores

Os resultados corroboram com estudos anteriores, indicando que a obtenção do título de mestre impulsiona os rendimentos. Isto deve-se em parte às novas oportunidades geradas, como crescimento e ascensão nas empresas, bem como a possibilidade de atuação em instituições de ensino superior, já que muitas exigem formação mínima em mestrado.

\subsection{Mestrado e a atuação profissional}

Outra etapa da pesquisa tinha como foco os motivos que levaram os egressos a iniciar um curso de mestrado. Neste ponto, cada item foi avaliado da seguinte forma: 'não pesou', 'pesou pouco', 'pesou médio' e 'pesou muito'. Entre os itens que foram avaliados com maior peso sobre a decisão, como mostra a Tabela 1, estão o de obter maior conhecimento, com 90\% das respostas em 'pesou muito'; aprimorar a atividade de pesquisador, para aqueles que provavelmente já exerciam atividade ligada à docência, com 58\% em 'pesou muito'; ampliar oportunidades de trabalho com $56 \%$ em 'pesou muito'. O mestrado pode abrir oportunidades que vão além da carreira na docência, como ingressar na atividade de pesquisador e alcançar prestígio profissional, que foram apontados por $48 \%$ em 'pesou muito', em ambos os casos.

Tabela 1 - Peso na decisão em fazer mestrado

\begin{tabular}{l|c|c|c|c}
\hline & Não pesou & Pesou pouco & Pesou médio & Pesou muito \\
\hline Obter maior conhecimento & $2 \%$ & $2 \%$ & $6 \%$ & $90 \%$ \\
\hline Aprimorar a atividade de pesquisador & $2 \%$ & $4 \%$ & $36 \%$ & $58 \%$ \\
\hline Ampliar oportunidades de trabalho & $4 \%$ & $6 \%$ & $34 \%$ & $56 \%$ \\
\hline Ingressar na atividade de pesquisador & $12 \%$ & $28 \%$ & $12 \%$ & $48 \%$ \\
\hline Alcançar prestígio profissional & $8 \%$ & $12 \%$ & $32 \%$ & $48 \%$ \\
\hline Suprir deficiências da graduação & $34 \%$ & $40 \%$ & $14 \%$ & $12 \%$ \\
\hline
\end{tabular}




\begin{tabular}{l|c|c|c|c}
\hline Ingressar na carreira docente & $14 \%$ & $18 \%$ & $28 \%$ & $40 \%$ \\
\hline Obter melhor nível de renda & $8 \%$ & $28 \%$ & $34 \%$ & $30 \%$ \\
\hline Aprimorar a carreira docente & $16 \%$ & $12 \%$ & $27 \%$ & $45 \%$ \\
\hline
\end{tabular}

Fonte: Elaborado pelos autores

Para $40 \%$ dos pesquisados, o item "ingressar da carreira docente" pesou muito na decisão de ingressar no mestrado, para $28 \%$ teve peso médio, para $18 \%$ pesou pouco e para $14 \%$ não pesou. Se for considerado que para aqueles que o ingresso na carreira docente pesou pouco e para aqueles que esse item não pesou, não possuem interesse em ingressar na docência, observase que $32 \%$ desses alunos obteve o título de mestre com outros objetivos, além da docência, o que mostra que o mestrado resulta em conhecimento e crescimento profissional para o mercado em geral.

Quanto às influências geradas pelo mestrado, como mostra a figura 3, observa-se que o item que mais influenciou a vida dos mestres em Contabilidade após a aquisição do título foi o espírito acadêmico, já que para 33\% dos egressos foi o item avaliado com grau de intensidade máximo, além desse, os itens amadurecimento profissional e produção acadêmica também foram avaliados com intensidade máxima para $28 \%$ dos egressos. Em contrapartida o item estabilidade profissional foi avaliado por $16 \%$ dos mestres como possuindo intensidade zero, ou seja, para esses egressos, o item não apresentou influência significativa após a conclusão do mestrado.

Figura 3 - Intensidade de influência após a conclusão do mestrado

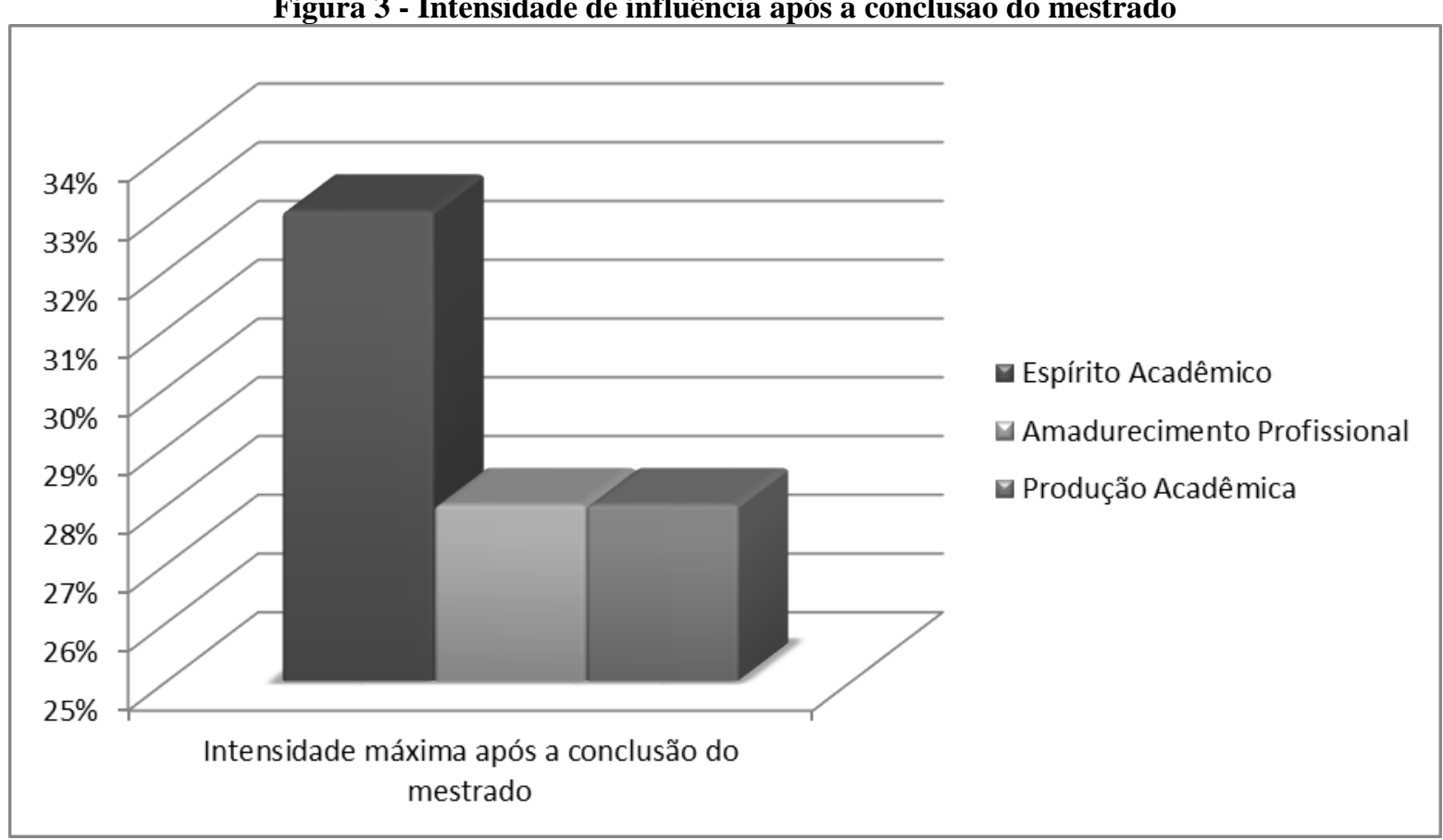

Fonte: Elaborado pelos autores

Em relação à continuidade dos estudos dos mestres em Contabilidade formados pela UFSC, foi perguntado se já haviam iniciado o doutorado e, $27 \%$ responderam que sim, sendo que desses que iniciaram o curso de doutorado, $21 \%$ já o concluíram. Em relação aos $73 \%$ que não iniciaram o curso de doutorado, foi perguntado se havia pretensão de iniciá-lo e, desses, $74 \%$ responderam afirmativamente. No estudo de Martins (2009) foi observado que $85,24 \%$ dos egressos não haviam iniciado o curso de doutorado, 1,04\% já havia concluído e 13,54\% estavam cursando durante a realização da pesquisa. Na pesquisa de Moraes (2009, p. 64), 28,5\% dos mestres havia dado continuidade em seus estudos em nível de doutorado, em função disso, o autor menciona que "o mestrado parece ser um ponto terminal no estudo da maioria dos mestres em Ciência Contábeis". 


\subsection{Atividade profissional após a conclusão do Mestrado}

A última etapa da pesquisa trata da atividade atual dos mestres pesquisados. Atualmente, $42 \%$ dos egressos possui a principal atividade remunerada ligada ao ensino (academia), o que mostra que após a conclusão do mestrado há uma migração dos egressos para atividades ligadas ao ensino, conforme figura 4.

Figura 4 - Principal atividade remunerada após a conclusão do mestrado

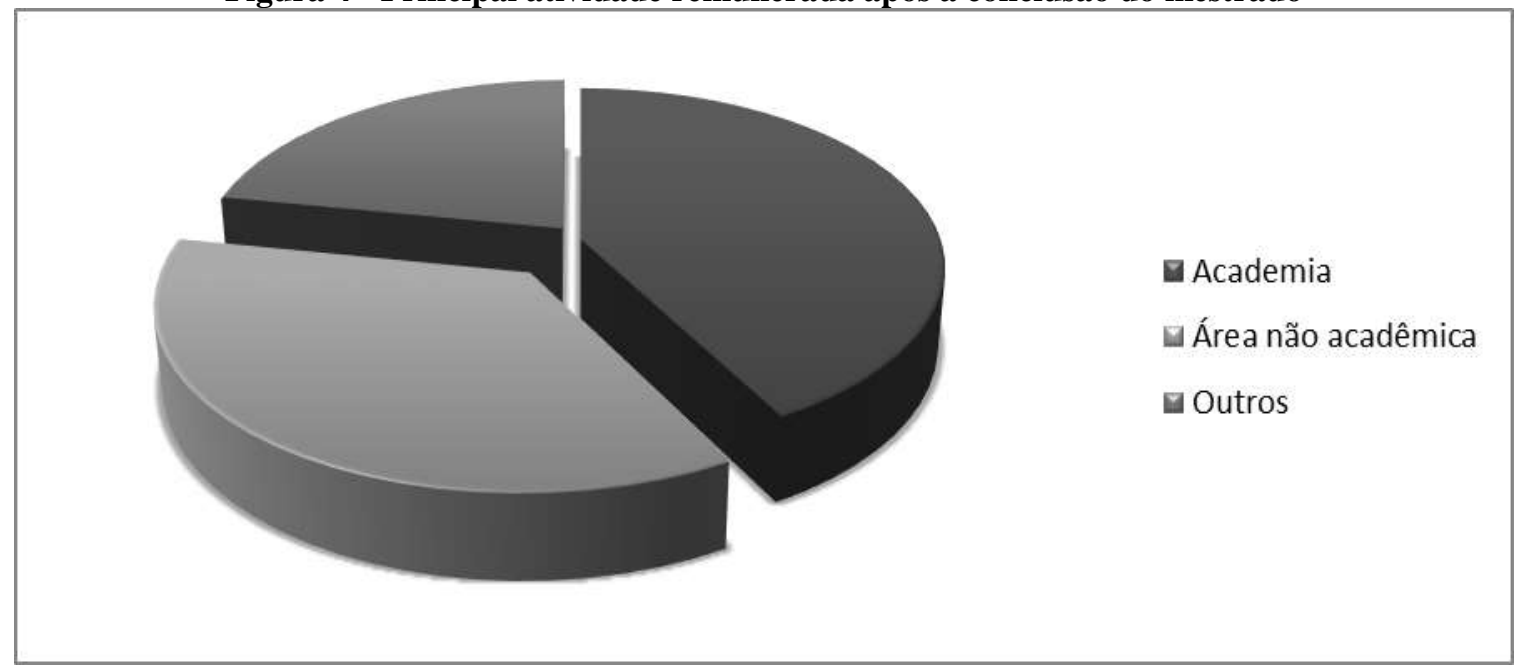

Fonte: Elaborado pelos autores

Do total de egressos, 54\% exercem atividade remunerada ligada à docência, e destes, $45 \%$ atuam em universidades, $35 \%$ em faculdades, $17 \%$ em centros universitários e $3 \%$ em outros, como pode ser visto na figura 5. Além disso, dos que exercem atividade ligada à docência, $63 \%$ o fazem em instituições privadas, sendo remunerados, em $46 \%$ dos casos por hora/aula. Destes que exercem atividade de ensino, $48 \%$ também atuam em pós-graduação lato sensu.

Figura 5 - Tipo de instituição onde exerce à docência

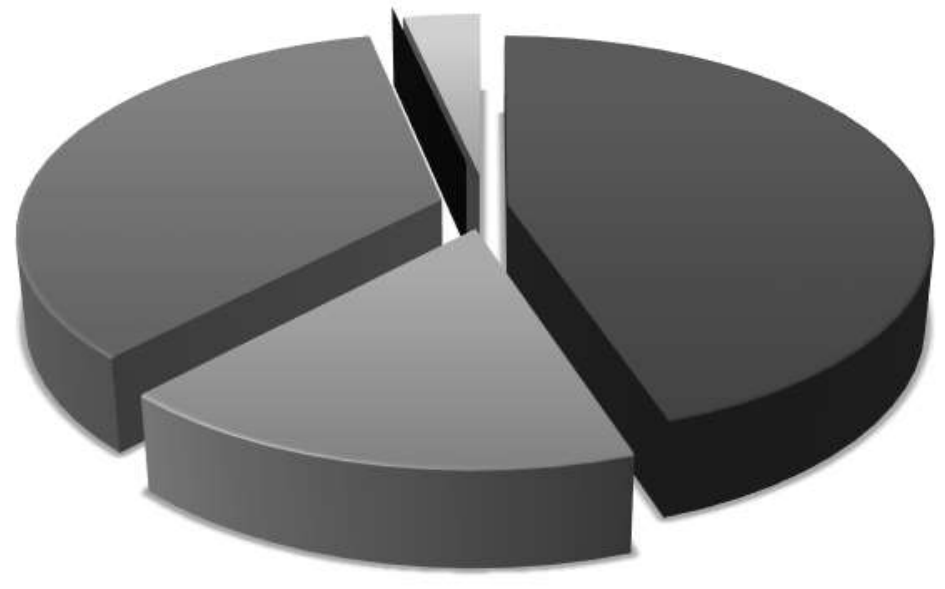

- Universidade

$\square$ Centro Universitário

Faculdade

aCEFET

$\square$ Outros

Fonte: Elaborado pelos autores

Outra questão abordada na pesquisa é a ligação dos mestres com a atividade de pesquisa, onde $49 \%$ do total de respondentes afirmam que sua atividade envolve a pesquisa e, $51 \%$ não possuem atividades ligadas à pesquisa. Como observa-se na figura $6,44 \%$ dos respondentes 
possui como principal atividade remunerada o setor público, seja exercendo a docência ou outras áreas.

Figura 6 - Relação de trabalho da principal atividade remunerada

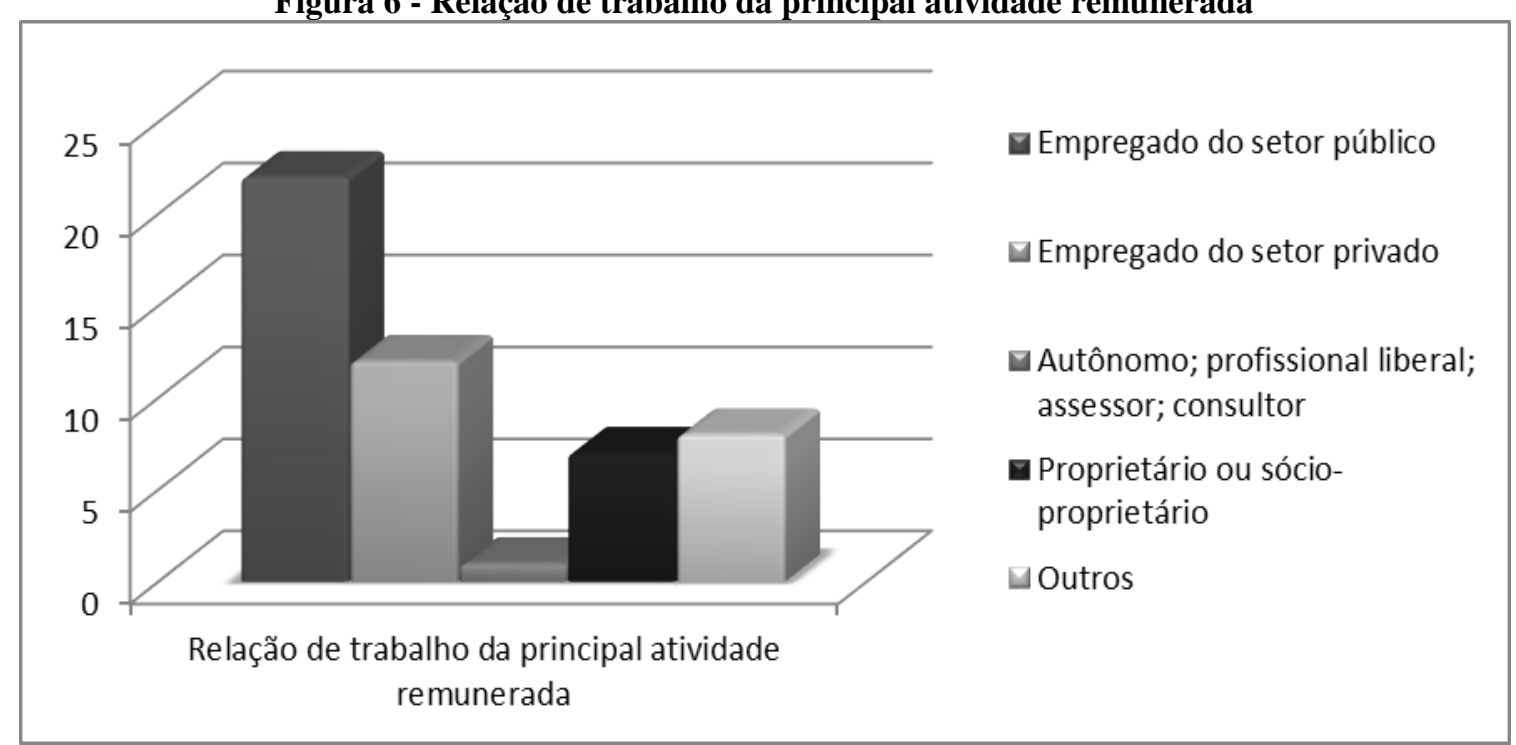

Fonte: Elaborado pelos autores

Em termos de remuneração, apenas $11 \%$ dos mestres pesquisados possuem rendimentos abaixo de $\mathrm{R} \$ 2.000,00$ (eram 28\% antes de iniciar o mestrado); aproximadamente $28 \%$ possuem rendimentos entre $\mathrm{R} \$ 2.001,00$ e $\mathrm{R} \$ 5.000,00$ (eram 40\% antes de iniciar o mestrado), cerca de $27 \%$ possuem rendimentos entre $\mathrm{R} \$ 5.001,00$ e $\mathrm{R} \$ 7.000,00$ (eram $20 \%$ antes de iniciar o mestrado), $16 \%$ possuem rendimentos entre $\mathrm{R} \$ 7.001,00$ e $\mathrm{R} \$ 9.000,00$ (eram $6 \%$ antes de iniciar o mestrado) e $18 \%$ possuem rendimentos acima de $\mathrm{R} \$ 9.000,00$ (eram $6 \%$ antes de iniciar o mestrado). Esse resultado corrobora com o do estudo de Martins (2009), onde a média salarial após a conclusão do mestrado foi apontada em $\mathrm{R} \$ 7.486,97$.

Figura 7 - Comparação entre as rendas antes de iniciar o mestrado e após a conclusão do mesmo 


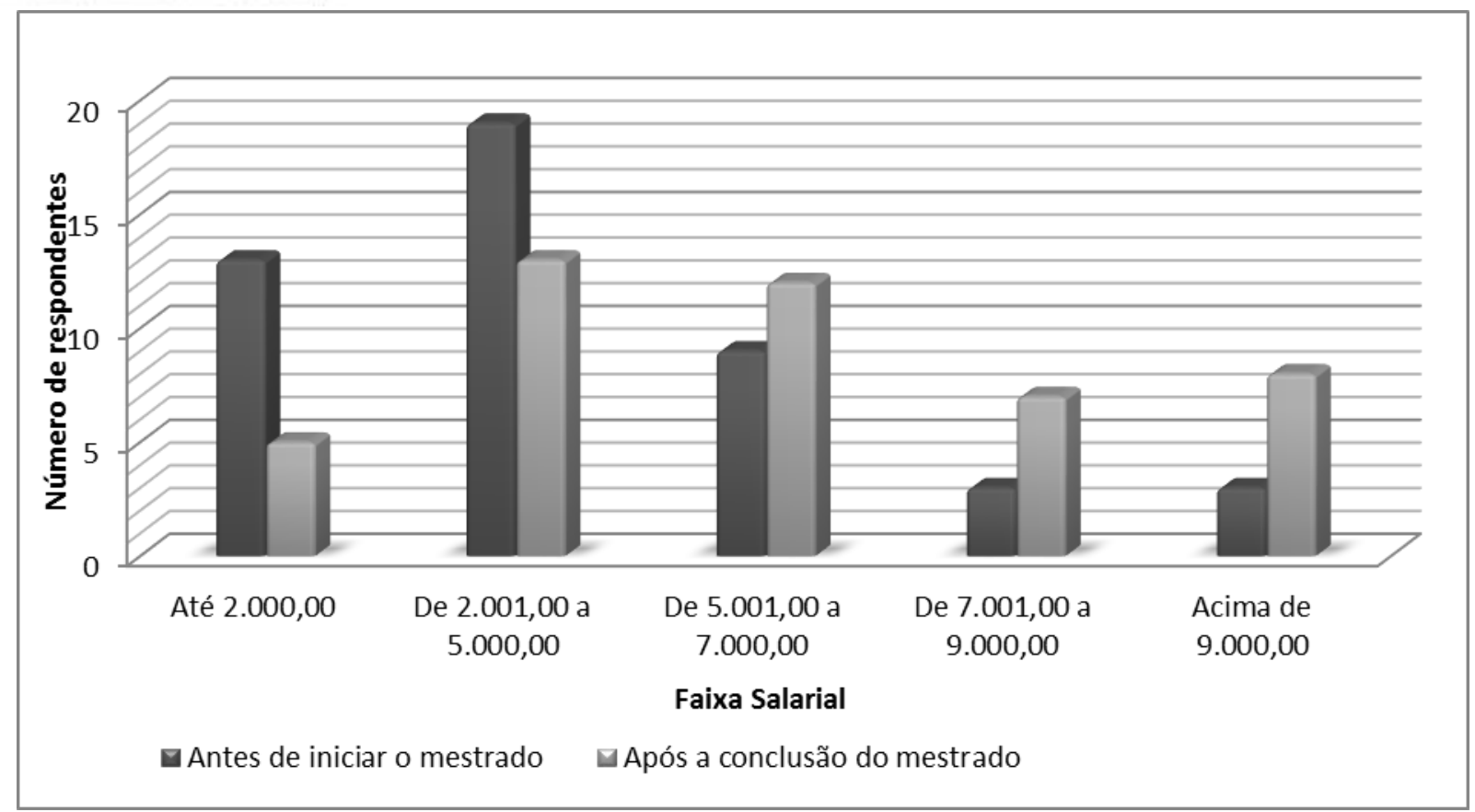

Fonte: Elaborado pelos autores

Antes de iniciar o curso de mestrado a maior parte dos pesquisados, cerca de $68 \%$, possuíam rendimentos até $\mathrm{R} \$ 5.000,00$ e após a conclusão do curso de mestrado $61 \%$ apresentam rendimentos a partir de $\mathrm{R} \$ 5.001,00$, o que demonstra que houve uma mudança na faixa salarial após a conclusão do mestrado.

\section{Conclusões}

O presente estudo teve como objetivo identificar o perfil de ocupação profissional e de renda dos egressos do Programa de Pós-Graduação em Contabilidade da Universidade Federal de Santa Catarina.

Por meio da aplicação de questionário a 51 egressos foi possível identificar que houve uma migração dos egressos do Programa pesquisado para atividades ligadas à academia, já que antes de possuírem o título de mestre, $18 \%$ atuavam na docência e após o título de mestre, esse percentual passou para 54\%. Desses, $48 \%$ também atuam em cursos de pós-graduação lato sensu e $3 \%$ em cursos stricto sensu. Além disso, antes de possuírem o título de mestre, apenas $27 \%$ possuíam à docência como principal atividade remunerada, e após a obtenção do título, $42 \%$ possuem à docência como atividade remunerada principal. Estes resultados assemelham-se aos encontrados por Moraes (2009), Dallabona, Oliveira e Rausch (2014) e Oliveira (2014) onde foi identificado a migração dos egressos para a carreira docente após a obtenção do título de mestre.

Em termos de continuidade da educação dos mestres em Contabilidade formados pela UFSC, $27 \%$ iniciaram o doutorado e dos que não iniciaram, $74 \%$ possuem pretensão de iniciar. Este item poderá sofrer uma modificação significativa visto que atualmente a UFSC também possui o curso de doutorado em Contabilidade, que iniciou em 2013.

Observa-se também que o título pode ter auxiliado na inserção dos mestres no setor público, visto que antes de iniciarem o curso de mestrado, $31 \%$ dos pesquisados exerciam a principal atividade remunerada no setor privado e após a obtenção do título de mestre esse percentual passou para 44\%. Isso pode ser explicado pelo fato de que os concursos públicos têm como parte da formação da nota final dos candidatos os títulos que estes possuem.

Em termos de remuneração observa-se que a obtenção do título de mestre possui influência positiva e auxiliou os egressos a obterem maiores rendimentos, como preconiza a Teoria do Capital Humano. Além disso, este achado corrobora com os de Cunha (2007), Moraes 
(2009), Martins (2009), Dallabona, Oliveira e Rausch (2014) e Oliveira (2014) que identificaram aumento das remunerações após a obtenção dos títulos.

Dessa forma, observa-se a aplicação da Teoria do Capital Humano entre os pesquisados, dado que houve impacto significativo e a titulação de mestre e doutor apresenta-se como um recurso importante para aqueles que procuram desenvolvimento pessoal e profissional, principalmente no que tange a inserção na carreira docente, sobretudo em instituições públicas, onde há a exigência de docentes com nível de mestrado, pelo menos.

Recomenda-se para futuros trabalhos a consideração de outros aspectos que possam ter sido influenciados pela obtenção do título de mestre ou doutor, como a qualidade de vida, a contribuição para pesquisa na área, entre outros.

\section{REFERÊNCIAS}

BECKER, G. S. Investment in human capital: a theoretical analysis. The Journal of Political Economy, Chicago, v. 70, n. 5, p. 9-49, oct. 1962.

BLAUG, M. Introdução à economia da educação. Tradução de Leonel Vallandro e Volnei Alves Corrêa. Porto Alegre: Globo, 1975.

BLAUG, M. The empirical status of human capital theory: a slighthy jaundiced survey. Journal of Economic Literature, Nashville, v. 14, n. 3, p. 827-855, sep. 1976.

CARVALHO, A. M. A. Onde estão e o que fazem nossos mestres e doutores? Uma reflexão sobre critérios de avaliação da pós-graduação. Brasília, 1999. Disponível em: < http://www.scielo.br/scielo.php?pid=S1414-98931999000200008\&script=sci_arttext\#top4>.

Acesso em: 08/06/2013.

COORDENAÇÃO DE APERFEIÇOAMENTO DE PESSOAL DE NÍVEL SUPERIOR CAPES. Plano Nacional de Pós-Graduação (PNPG) - 2005-2010. Brasília, 2004. Disponível em: 〈http://www.capes.gov.br/images/stories/download/editais/PNPG_2005_2010.pdf>. Acesso em: 17/05/2013.

COORDENAÇÃO DE APERFEIÇOAMENTO DE PESSOAL DE NÍVEL SUPERIOR CAPES. Relatório de Gestão do Exercício de 2013. Brasília, 2014. Disponível em: < https://www.capes.gov.br/images/stories/download/Contas_Publicas/Relatorio-de-Gestao2013.pdf>. Acesso em: 03/04/2016.

CUNHA, J. V. A. Doutores em Ciências Contábeis da FEA/USP: Análise sob a óptica da Teoria do Capital Humano. Tese de Doutorado, São Paulo, 2007.

CUNHA, J. V. A.; CORNACHIONE JUNIOR, E. B.; MARTIN, G. de A. Doutores em Ciências Contábeis: Análise sob a Óptica da Teoria do Capital Humano. RAC, Curitiba, v. 14, n. 3, art. 8, pp. 532-557, Mai./Jun., 2010.

DAllabonA, L. F.; OliveirA, A. F. de; RAUSCH, R. B. Avanços Pessoais e Profissionais Adquiridos por meio da Titulação de Mestre em Ciências Contábeis. Contabilidade Vista \& Revista, v. 24, n. 2, p. 39-62, 2014. 
FERREIRA, P. L. L. Impactos do capital humano no crescimento econômico do Brasil, entre 1977 e 2005. 2008. 93f. Dissertação (Mestrado em Economia) - Faculdade de Ciências Econômicas, Universidade do Estado do Rio de Janeiro, Rio de Janeiro, 2008.

GIL, A. C. Como Elaborar Projetos de Pesquisa. 4. ed. São Paulo: Atlas, 2002.

LIMA, R. Mercado de trabalho: o capital humano e a teoria da segmentação. Pesquisa e Planejamento Econômico, Rio de Janeiro, v. 10, n. 1, p. 217-272, abr. 1980.

MACHADO, M. R. O resultado econômico-financeiro proporcionado aos profissionais mediante conclusão de Cursos de Pós-Graduação Lato Sensu em Contabilidade, 1988-2001. Dissertação de Mestrado, Paraíba, 2003.

MARTINS, O. S. Mestres em Ciências Contábeis pelo Programa Multiinstitucional da UNB/UFPB/UFPE/UFRN: Uma análise a partir de suas percepções e avaliações. Dissertação de Mestrado, Paraíba, 2009.

MENEZES-FILHO, N. A. A Evolução da educação no Brasil e seu impacto no mercado de trabalho. FEA/USP (mimeo), São Paulo, 2002.

MORAES, R. O. Mestres em Ciências Contábeis sob a óptica da Teoria do Capital Humano. Tese de Doutorado, São Paulo, 2009.

NERI, M. O retorno da educação no mercado de trabalho. Rio de Janeiro: Centro de Políticas Sociais do IBRE/FGV e da EPGE/FGV, 2005.

NERI, M. O retorno da universidade. Disponível em: <http://www.cps.fgv.br/cps/artigos/Conjuntura/2005/hc353.pdf >. Acesso em: 08/06/2013.

OliveIRA, N. dos S. A Atuação Profissional e a Situação Socioeconômica dos Mestres Formados pelo Programa de Pós-Graduação em Ciências Contábeis Mestrado em Contabilidade da UFBA. Revista de Administração e Contabilidade da FAT, v. 6, n. 2, p. 3649, 2014.

PROGRAMA DE PÓS-GRADUAÇÃO EM CONTABILIDADE. Universidade Federal de Santa Catarina. Disponível em: 〈http://www.ppgc.ufsc.br/>. Acesso em: 20/04/2013.

RICHARDSON, R. J. Pesquisa social: métodos e técnicas. São Paulo: Atlas, 1985.

SCHULTZ, T. W. Investment in human capital. The American Economic Review, Cambridge, v. 51, n. 1, p. 1-17, mar. 1961.

TRIVIÑOS, A. N. S. Introdução à pesquisa em ciências sociais: a pesquisa qualitativa em educação: 1.ed. São Paulo: Atlas, 1987. 